\title{
Response Time and Causes of Delay in Prehospital Emergency Missions in Mashhad, 2015
}

\author{
Mehdi Jafari $^{1}$, Payam Mahmoudian ${ }^{1} * \mathbb{D}$, Hossein Ebrahimipour ${ }^{2}$, Reza Vafaee-Nezhad ${ }^{3}$, Ali Vafaee-Najar ${ }^{2}$, \\ Seyede-Elahe Hosseini ${ }^{4}$, Hajar Haghighi ${ }^{5}$
}

Received: 18 Nov 2018

Published: 27 Oct 2021

\section{Abstract}

Background: The response time is considered as one of the most important criteria for the quality of given care to the injured. This research aimed to investigate the frequency and causes of prehospital emergency delays in the 115 emergency center, in city of Mashhad, in 2015

Methods: In this cross-sectional study, 21,142 missions performed in 2015 were investigated, from among which 640 missions with delays in systematic sampling were recognized. For data analysis purposes, descriptive statistics (frequency, mean and SD) in Excel 2013 software was implemented.

Results: Nearly $60 \%$ of the injured were men, $23 \%$ women, and the gender of $17 \%$ was not recorded in their profiles. The mean age of the injured was $29.8+15.9$ years and $30 \%$ of the injured were in the age group of 16 to 25 . The mean response time was 9:01+2:46. The most prevalent causes related to missions out of the operational zone $(29.3 \%)$ and the second cause has been related to traffic groups $(24.2 \%)$.

Conclusion: Establishing new bases and completing the number of ambulances and human recourses, intervention in traffic causing factors, and training the public about emergency cases can be effective in reducing the number of missions and the pace and quality of services provided to the injured.

Keywords: Response Time, Causes of Delay, Prehospital Emergency, Iran

Conflicts of Interest: None declared

Funding: Mashhad University of Medical Sciences

*This work has been published under CC BY-NC-SA 1.0 license.

Copyright $\odot$ Iran University of Medical Sciences

Cite this article as: Jafari M, Mahmoudian P, Ebrahimipour H, Vafaee-Nezhad R, Vafaee-Najar A, Hosseini SE, Haghighi H. Response Time and Causes of Delay in Prehospital Emergency Missions in Mashhad, 2015. Med J Islam Repub Iran. 2021 (27 Oct);35:142. https://doi.org/10.47176/mjiri.35.142

\section{Introduction}

Road accidents is the second most common cause of death in Iran, with $57 \%$ of victims succumbing to their injuries before reaching to hospital. Over the past decade, 235,050 people have been killed and 2,0221,000 people injured in motor vehicle accidents. According to the statistics, in 2012, Iran reported 1160 injuries and 26.75 deaths

Corresponding author: Payam Mahmoudian, payam_mahmoudian@yahoo.com

1. Department of Health Services Management, School of Health Management and Information Sciences, Iran University of Medical Sciences, Tehran, Iran

2. Social Determinants of Health Research Center, Mashhad University of Medical Sciences, Mashhad, Iran

3. Emergency Medical Services Center, Mashhad University of Medical Sciences, Mashhad, Iran

4. Student Research Committee, School of Health Management and Information Sciences, Isfahan University of Medical Sciences, Isfahan, Iran

5tudent Research Committee, School of Public Health, Health Management and Economics Department, Tehran University of Medical Sciences, Tehran, Iran per 100,000 people. Accidents, besi des the loss and damages they cause, have consequences such as damages and injuries which are not bearable by the societies (1).

According to the principle of fair access to health services, the goal of an emergency response center is providing medical care to people in need; in other words, the

$\uparrow$ What is "already known" in this topic:

In other studies, only the response time and reasons for the delays in the special record forms were investigated.

\section{$\rightarrow$ What this article adds:}

In this study, to determine the reasons for the prehospital emergency delay, in addition to examining the time recorded in documents, we used the global positioning systems on ambulances to determine that the ambulance routing had been right. 
emergency medical service is a response to special health requirements of people out of the hospitals $(2,3)$. According to the World Health Organization, in Iran, in 2012, every 24 hours, 69 people and every year nearly 25000 people lose their lives to accidents (4).

Considering this shocking statistics, the aid system to the injured suffers from various faults, such as delay in the arrival of the 115 emergency services to the injured, lack of sufficient medical tools and expert and trained personnel, and improper culture of people confronting crisis occasions (5).

Emergency needs to avoid any delay in providing medical services. In this respect, the pace of providing services in the centers and, specially, in the emergency wards of prehospital centers is very important in reducing the number of deaths and disabilities (6). It seems that the response time is among the most significant criteria for the traumatic patients. Measuring these time durations can be an important step in evaluating the performance of the emergency system of the prehospital sectors (7). The response time of the ambulances, which is defined as the time from the starting point for primary response until the arrival of care to the accident scene, has gained major significance in the industry and public organizations (8). The more faultless, safer, and faster care for critical patients delivered by the EMS, the less mortality and disability resulting from illnesses and diseases will be witnessed. Consequently, this would increase the people's trust on the system. The arrival time to the patients is considered as the response time, which plays a vital role in increasing the chances of the survival of the patients and reducing the side effects. Considering the statistics worldwide, the arrival time of ambulances, less than 8 minutes, in cardiovascular patients decreases the number of deaths and reduces the effects of this sort of incidents (4). Effective leadership is critical to controlling such situations (9) because the health sector is one of the most important service industries and should evaluate and improve its quality in order to achieve the desired results (10).

The response time is more than the global standards in most Iranian major cities. A study in Iran showed that death in prehospital sectors, emergency wards, and hospitals are $42 \%, 20 \%$, and $37 \%$, respectively, which include trauma deaths. Therefore, the prehospital care has a vital role in the life of human beings (11). The results of the study performed by Panahi in Tehran shows that the response time is 14.98 minutes (5). In Moradian study, half of the missions took 8 to 10 minutes and more than the standard time (6), and in Weiser study in Australia (12), this time has been equal to 12.08 minutes. In this study, to determine the reasons for the prehospital emergency delay, in addition to examining the time recorded in documents, we used the GPS system on ambulances to determine that the ambulance routing had been right.

Mashhad is considered as the medical hub in northeast of Iran so the hospital centers in the city are one of the most visited hospitals in the country (13). Mashhad is located in the northeast of Iran and is the center of Khorasan Razavi province. According to statistics, the 12th municipality neighborhood in Mashhad has the area of equal to
3/352 square kilometer. Also, according to the last census of the Islamic Republic of Iran, the resident population of Mashhad is 3,372,660 and after Tehran, it is the second most populous city in Iran (14). Because of the holy shrine of Imam Reza in Mashhad, this city receives countless travelers and pilgrims from all parts of Iran and the world every year. The mean daily arrival of the travelers and pilgrims in Mashhad by fleet air, rail, and road is 9327, 16495 and 11,401 respectively. Mashhad during the years of the study had 12 hospitals in the city and 37 urban-based 115 emergency centers, and 52 emergency ambulances affiliated to Mashhad University of Medical Sciences (15).

Considering the importance of the emergency centers in providing vital and immediate care and considering the factor of time as one of the main pillars of services in these centers, with proper response and limitation in health sector resources and also implementing time management tools, better care andl results can be obtained in the health system $(16,17)$. Therefore, this research was done to define the response time and causes for delays in prehospital emergency (115) in Mashhad in 2015.

\section{Methods}

This was a descriptive cross-sectional and applied study. The documents studied in this study are related to accident injuries in Mashhad. The study population to determine the most important causes of delays includes 11,268 missions, with delays from July 2014 to the end of June 2015 (12 months). (Delayed missions: Missions that are more than 8 minutes from the time of contacting the emergency center until the ambulance arrives at the scene).

Data collection was done in 2 stages: (1) Preparing the checklist of causes for the delay, (2) determining the most important causes for delays.

In the first stage, to prepare the checklist for the causes of delay, first, the delayed missions were reviewed by the experts of the monitoring unit of the Medical Emergency and Accident Center of Mashhad University of Medical Sciences.

For additional information, the causes for the delay were received from the technicians by phone, and since the ambulances were equipped with a GPS, the routes of the ambulances were checked to check the route chosen by the technician, and the list of causes by experts of the center were prepared. In the next step, the documents of delayed missions were reviewed by the research team and the delayed causes recorded in the files were extracted.

Finally, the causes determined by the experts of the monitoring unit and the research team were combined and duplicate and similar causes were eliminated, and the initial checklist was obtained with 27 causes for the delay.

The prepared checklist was reviewed in a meeting with the presence of experts and managers of the Emergency Medical Center, and finally the checklist was approved with 10 main causes and 17 subsets.

In the second stage, to determine the most important causes of delay, the sample size of 640 was determined and the files were selected by systematic random sampling 
(K: 18) using the PASS (Power Analysis and Sample Size) software. Then, after the checklist was approved in the first step, the number of times of each cause was recorded in the files. Finally, using Excel 2013 software and descriptive statistics, the obtained data were analyzed and the most important causes of delay were identified.

\section{Results}

Approximately, $60 \%$ of the injured were men, $23 \%$ women, and the gender of $17 \%$ were not recorded. The mean age of the injured was $29.8 \pm 15.9$; almost $30 \%$ of the injured aged between 16 to 25 years. The mean timing of performing a mission from the time receiving the message until reaching the injured by the ambulance was estimated 9:01 $\pm 2: 46$ and approximately $52 \%$ of the missions were performed more than 8 minutes.

Most important causes of delays were as follows: mis- sions out of the area of operation; traffic; delays relating to manpower; lack of quick access to the scene; incorrect address; long distance to the scene; the mission dispatch from the end of other missions; errors in timekeeping records; the mission was on the road; and the ambulance was replaced during the mission.

In Table 1, the most frequent cause of delays were related to missions out of the operation area of the emergency base (29\%), in which $55 \%$ of cases required dispatching a second ambulance. The second cause was due to traffic $(24 \%)$, in which the most cases in this category were related to traffic on the way to the scene (84\%).

Most missions with a delay were in summer $(28.9 \%)$, and then in the spring $(27.25 \%)$. Most delays in the summer were due to traffic on the way $(23.25 \%)$ and the missions out of the operation area of the emergency base $(22.37 \%)$. Most missions with a delay occurred during 6 and 9 PM (22.48\%), followed by 12 noon to 3 PM

\begin{tabular}{|c|c|c|c|c|c|}
\hline Priority & Cause Of Delay & Subset & Frequency & Percent & $\begin{array}{l}\text { Percent of } \\
\text { Total }\end{array}$ \\
\hline \multirow[t]{8}{*}{1} & Missions Out of The & The First Ambulance on Mission & 128 & 55.17 & 16.18 \\
\hline & Area of Operation & The Second Ambulance Dispatch & & & \\
\hline & & The First and Second Ambulance on Mission & 64 & 27.59 & 8.09 \\
\hline & & Third Ambulance Dispatch Closer & & & \\
\hline & & Ambulance First, Second, and Third in the Mission & 24 & 10.34 & 3.03 \\
\hline & & Fourth Ambulance Dispatch & & & \\
\hline & & $\begin{array}{l}\text { Ambulance First, Second, Third, and Fourth in the Mission } \\
\text { Fifth Ambulance Dispatch }\end{array}$ & 12 & 5.17 & 1.52 \\
\hline & & $\begin{array}{l}\text { Ambulance First, Second, Third, Fourth, and Fifth Mission } \\
\text { Sixth Ambulance Dispatch }\end{array}$ & 4 & 1.72 & 0.51 \\
\hline \multirow[t]{2}{*}{ Total } & & & 232 & 100 & 29.33 \\
\hline & & Traffic on The Way to The Scene & 164 & 85.42 & 20.73 \\
\hline \multirow[t]{3}{*}{2} & Traffic & Traffic in The Place Of Incidence & 23 & 11.98 & 2.91 \\
\hline & & Traffic Intersections to The Scene & 5 & 2.60 & 0.63 \\
\hline & & Total & 192 & 100 & 24.27 \\
\hline \multirow[t]{2}{*}{3} & Manpower Delay & $\begin{array}{l}\text { Delays By Technicians of Emergency Base Moving Toward } \\
\text { the Incident }\end{array}$ & 99 & 86.09 & 12.52 \\
\hline & & $\begin{array}{l}\text { Delay By the Command Center Operator In Mission An- } \\
\text { nounce To The Base }\end{array}$ & 16 & 13.91 & 2.02 \\
\hline Total & & & 115 & 100 & 14.54 \\
\hline \multirow[t]{5}{*}{4} & Lack Of Quick Access & No U-Turn in The Range of Incident & 36 & 43.90 & 4.55 \\
\hline & To Scene & Being Blocked in Front of The Base By Bus & 6 & 7.32 & 0.76 \\
\hline & & $\begin{array}{l}\text { Difficult Access to The Accident Site } \\
\text { (Terrestrial Routes, Close Exits, Building Operation, High } \\
\text { Intersections, One-Way Streets, The Lack of Alleys Names, } \\
\text { The Name of Some Alleys and Streets in the City, Alleys } \\
\text { and Streets } 100 \text { Meters) }\end{array}$ & 35 & 42.68 & 4.42 \\
\hline & & The Large Number of Red Lights on the Way to the Scene & 3 & 3.66 & 0.38 \\
\hline & & $\begin{array}{l}\text { The Problem of Ambulances Exit Door } \\
\text { At the Bases }\end{array}$ & 2 & 2.44 & 0.25 \\
\hline Total & & & 82 & 100 & 10.37 \\
\hline \multirow[t]{2}{*}{5} & Incorrect Address & Wrong Address by the Police & 3 & 9.38 & 0.38 \\
\hline & & $\begin{array}{l}\text { Address Wrong and Incomprehensible } \\
\text { Of Caller and Command Center Operators }\end{array}$ & 29 & 90.63 & 3.67 \\
\hline Total & & & 32 & 100 & 4.05 \\
\hline 6 & \multicolumn{2}{|l|}{ Long Way to the Scene } & 76 & & 9.61 \\
\hline 7 & \multicolumn{2}{|c|}{ The Mission Dispatch from the End Of Other Missions } & 19 & & 2.40 \\
\hline 8 & \multicolumn{2}{|c|}{ Errors in Timekeeping Records } & 14 & & 1.77 \\
\hline 9 & \multicolumn{2}{|c|}{ The Mission Was on the Road } & 5 & & 0.63 \\
\hline 10 & \multirow{2}{*}{\multicolumn{2}{|c|}{ Ambulance Been Replaced During the Mission }} & 2 & & 0.25 \\
\hline Total & & & 791 & & 100 \\
\hline
\end{tabular}


(21.07\%). The most common cause $(34.1 \%)$ was during 6 to $9 \mathrm{PM}$ and on missions out of the operation area of the emergency base.

\section{Discussion}

This study aimed to determine the response time and prevalence of major causes of delay in prehospital emergency (115) of Mashhad in 2015.

\section{Determining the Response Time to Emergencies}

Considering the importance of time management in prehospital emergencies, in this study, $54 \%$ of the missions were over the standard time, about 9 minutes and $1 \mathrm{sec}-$ ond. The most important period in emergency situations is "response time" and based on the standards and regulations of prehospital emergency service universal coverage, $80 \%$ of urban emergency missions should be performed under 8 minutes (18).

In this study, about $46 \%$ of the missions were performed under 8 minutes and the mean of the distance was too far away from the standard time. In the study by Mohammadi in 2015, the response time was equal to 7 minutes and 28 seconds (19), Moradian in 2013 found that about 50\% of the missions are done in 8 to 20 minutes (6). In the study of Rahbar Taramsari in 2014, response time was estimated to be 6 minutes and 45 seconds (20) and in the study of Bidari in 2006, the response time was equal to 12 minutes and 54 seconds (21). Sladjana (2012) indicated that the response time was equal to 7 minutes and 5 seconds (22). Jack Campbell in 2007, declared that response time was equal to 9 minutes and 48 seconds (23). In a study in Australia by Weiser (12) 12.08 minutes was achieved.

\section{Determining the Causes of Delays in the Mission of the Emergency Center}

The findings revealed that the main causes for delay are missions out of the operation area of the emergency base. This means, in the defined area, the ambulance was on the mission. To deliver the services, the closest ambulance in the area of mission should be dispatched to the scene. The cause of $29 \%$ missions with delays was missions out of the operation area of the emergency base; this group includes 5 subgroups; and the most frequent cause of delay $(55 \%)$ was that the first ambulance was not available, therefore, the second ambulance was dispatched. It seems that the main cause for the delays is shortage of bases and lack of sufficient ambulances for emergency missions. Therefore, increasing the number of bases and the number of ambulances as well as implementing "motorlance" (motor-ambulances) is recommended.

The second cause for the delays in the 115 emergency missions was traffic (24\%); this cause included 3 subsections: (1) traffic on the way, (2) traffic at the place of the incidence, and (3) the traffic intersections to the scene; $85 \%$ of delays were due to traffic on the way. Ayrik $\mathrm{Cu}-$ neyt (2006) implied that traffic is one of the causes for sending cardio vascular patients (24). It seems that use of Green Mile (a plan aimed to improving traffic control in the path of ambulance while on a mission), cultural domination practices in opening the way of the ambulances in the streets and crowded intersections can be effective.

The third cause $(14.5 \%)$ was related to manpower. This cause consists of 2 parts, and $86 \%$ related to delays in moving from the emergency base and $14 \%$ related to errors made by operator experts at the emergency command center.

Missions out of the operation area are due to lack of the emergency base and an ambulance. In a way that in some investigations, it was found out that for every 50,000 people one or more ambulanices and staff are required. The current situation is far from being a desired standard level, and the present time this shortage is compensated by increased workload of other emergency bases.

In a study by javad Moradian et al in 2013 (6), the causes for delay were such reasons as the dispatch from other regions $(50 \%)$, traffic on the away $(22 \%)$, and distant places (19\%). In a study by Assar-roudi (25) in 2006, the most important causes were time wasted by dispatching nonemergency missions and poor road texture.

Jarrell et al also in their study have indicated the importance of distribution of ambulances. They noted the poor management in the distribution of ambulances in different areas is effective in the long-term response (26).

In this respect, increasing staffing in the emergency base and command center and emergency communications in Mashhad and reducing human intervention in ambulance selection and using an intelligent software to determine the appropriate ambulance closer to the event were recommended to reduce delays in emergency missions.

Indicated cases and other studies have identified the major cause of delay in emergency missions (115) to be dispatches from other bases because of the lack of sufficient human resources, ambulances, and emergency bases. Also, emergency bases in an urban area are not functioning well and this lack of proper structure is a reason for the delays and developing the area in need for emergency coverage and delay in providing on time care. The limitation of this study was that due to the confidentiality of the organization's information, the information required was provided to the researcher in different time intervals, which delayed the research process.

\section{Conclusion}

Given that in this study, response time was more than the standard time ( 9 minutes 1 second), it is required to reduce the response time in emergency missions. Reducing the emergency response time in emergency missions (115) requires the attention of authorities at the Ministry of Health and Treatment and Medical Emergency to this issue. In addition to allocating more funds to this sector, accurate need assessment of the number of ambulances, emergency equipment, and database requirements should be done according to population density and people's needs and demands.

The most important reason in delays in 115 emergency centers in Mashhad was providing services to areas located out of the range of the base. This reason has conse- 
quences such as improper distribution and long distances to reach the emergency area, fatigue, commuting the patients from distant points, and long durations and delay in returning to the bases to perform other missions. Establishing new bases, increasing the number of ambulances, and also increasing public awareness with respect to the emergency cases can reduce the number of missions and improve the distributions of missions among the bases. Moreover, using motorcycles can be an alternative to EMS missions in rush hours.

\section{Acknowledgement}

The current study was done with the financial support of the research and development deputy of transportation of Mashhad municipality. The emotional and official support of the Center of Accident and Emergency Management of Mashhad University of Medical Sciences and the cooperation of Mashhad University is highly appreciated (code: 922674). The authors of the article specially appreciate the efforts of Mashhad 115 emergency center. Also, the authors are grateful to Behnam Jabini and abolfazl Ghotbi.

\section{Conflict of Interests}

The authors declare that they have no competing interests.

\section{References}

1. Bahadori M, Ghardashi F, Izadi AR, Ravangard R, Mirhashemi S, Hosseini SM. Pre-hospital emergency in Iran: A systematic review. Trauma Mon. 2016;21(2)

2. Vafaee-Najar A, Khabbazkhoob M, Alidadi-Soltangholi H, Asgari S, Ibrahimipour H. Investigating the relative risk factors of injuries caused by accidents on roads in the Mashhad area in 2007. Iran Red Crescent Med J. 2011;13(8):530.

3. Rezapour A, Azar FE, Aghdash SA, Tanoomand A, Shokouh SMH, Yousefzadeh $\mathrm{N}$, et al. Measuring equity in household's health care payments (Tehran-Iran 2013): technical points for health policy decision makers. Med J Islam Repub Iran. 2015;29:246.

4. Soltani M, Asadi-manesh L, Rajabi Z. Evaluating the time required for the presence of EMS in the event. Sci J Rescue Relief. 2013;4(3):6778 .

5. Panahi F, Mohebbi HA, Azizabadi-Farahani M, Khoddami-Vishteh HR, Assari S. Prehospital Emergency Service for Internal Medicine Problems in Pediatrics; Causes, Time Indices and Outcomes. Iran J Pediatr. 2007;17(2):179-85.

6. Moradian MJ, Peyravi M, Etehadi R, Pour-Mohammadi K. Examine the cause of delay in responding to the emergency and missions of urgent care center 115 in Shiraz. Sci J Rescue Relief. 2013;5(2):30-9.

7. Bigdeli M, Khorasani-Zavareh D, Mohammadi R. Pre-hospital care time intervals among victims of road traffic injuries in Iran. A crosssectional study. BMC Public Health. 2010;10(1):1.

8. Pons PT, Markovchick VJ. Eight minutes or less: does the ambulance response time guideline impact trauma patient outcome? J Emerg Med. 2002;23(1):43-8.

9. Azar FE, Asiabar AS. Does leadership effectiveness correlates with leadership styles in healthcare executives of Iran University of Medical Sciences. Med J Islam Repub Iran. 2015;29:166.

10. Jafari M, Nemati A, Mahmoudi MS, Seyedin H, Hosseini SE, Rakhshan A, et al. Implementation effect of specialist residency program: A case study on performance indicators of emergency departments. Int J Healthc Manag. 2018:1-10.

11. Bahrami M, Ranjbar-Ezzatabadi M, Maleki A, Asqari R, AhmadiTehrani G. A Survey on the Yazd Pre-hospital Emergency Medical Services' Performance Assessment, 2009-2010. J Sch Health. 2010;9(9):45-59.

12. Weiser C, Van-Tulder R, Novosad H, Hopfgartner A, Sterz F,
Schreiber W. EMS response time for cardiac arrest patients in a rural area of Austria. Resuscitation. 2010;81(2):87.

13. Ebrahimipour H, Vafaei Najjar A, Khani Jahani A, Pourtaleb A, Javadi M, Rezazadeh A, et al. Health system responsiveness: a case study of general hospitals in iran. Int $\mathrm{J}$ Health Policy Manag. 2013;1(1):85-90.

14. https://www.amar.org.ir/ [Internet]]. 2017.

15.http://www.mashadtraffic.ir/en/porttal/component/content/frontpage.h tml.

16. Skinner R. Improving ambulance estimated time of arrival (ETA) at hospital emergency department. Health GIS Guy. 2008;6:78-9.

17. Sadat Sajjadi H, Hesam Seyedin S, Zaboli R, Abedi G, Sheikh Gholami S. The effectiveness of contact thermography in the diagnosis of disease: a systematic review. Razi J Med Sci. 2011;18(84).

18. Regulations of organizing compriehensive coverage of pre-hospital emergency medicine services Country, (2008).

19. Mohammadi M, Nasiripour A, Fakhri M, Bakhtiari A, Azari S, Akbarzadeh A, et al. The Evaluation of Time Performance in the Emergency Response Center to Provide Pre-Hospital Emergency Services in Kermanshah. Glob J Health Sci. 2015;7(1):274.

20. Rahbar-Taramsari M, Badsar A, Naghipour M, Dvam F, Shahrami $\mathrm{H}$, Saeidinia A, et al. Assessnnent of pre-hospital emergency performance in missions of 115 emergency bases of Rasht, Iran. Ann Biol Res. 2013;4(12):75-81.

21. Bidari A, Abbasi S, Farsi D, Saeedi H. Performance evaluation of pre-hospital care of patients transferred to hospital , the Holy Prophet (PBUH ). Med J Tabriz Univ Med Sici Health Serv. 2006;29(3):46-3.

22. Sladjana A, Gordana P, Ana S. Emergency response time after outof-hospital cardiac arrest. Eur J Intern Med. 2011;22(4):386-93.

23. Campbell J, Kroshus K, Lindhollm D, Watson W. Measuring the call-receipt-to-defibrillation interval: evaluation of prehospital methods. Ann Emerg Med. 1995;261(6):697-701.

24. Cuneyt A, Ulku E, Ozan K, Cerm N, Belgin U, Oktay E. Factors influencing emergency department arrival time and in-hospital management of patients with acute myocardial infarction. Adv Ther 2006;23(2):244-55

25. Assar-Roudi A. The Causes of Late Arrival of Pre-Hospital Emergency from the Point of View of Clinical Emergency Personnel of the 115 of Mashhad in 2006. Dena J. 2009;3(3,4):10-6.

26. Jarrell B, Tadros A, Whiteman C, Crocco T, Davis S. National Healthline Responses to a Stroke Scenario Implications for Early Intervention. Stroke. 2007;38(8):2376-8. 